\title{
Appropriation of Resources by Bilingual Students for Self-Regulated \\ Learning of Science
}

Jingjing $\mathrm{Hu}$

Faculty of Education, The University of Hong Kong Hong Kong

Xuesong (Andy) Gao*

School of Education, University of New South Wales Australia

*Corresponding author

Xuesong (Andy) Gao

School of Education, Level 1, John Goodsell Building, University of New South Wales, High

Street, Randwick, NSW 2052, Australia

xuesong.gao@unsw.edu.au 


\section{Appropriation of Resources by Bilingual Students for Self-Regulated}

\section{Learning of Science}

This study draws on the activity theory to explore how bilingual first-year secondary school students appropriate resources strategically in response to linguistic challenges in learning science through English in Hong Kong. The study explored 12 bilingual students' self-regulated strategy use by conducting in-depth interviews, stimulated recalls, observation and analysis of learning materials. Through analyzing these data, we examined how and why they appropriated and used resources strategically for self-regulated learning. The analysis revealed that the participants had used various artefacts (e.g., dictionary) and rules (e.g., evaluation criteria) to negotiate their respective roles (e.g., subject content learners and language learners) in situated communities of learning that consist of subject teachers, classmates, family members, private tutors and friends. Similarities and differences were found between the high achievers and the underachievers with regard to the use of resource-mediated strategies and the underlying reasons. The results inform the development of pedagogical schemes to enhance bilingual students' self-regulated strategic learning of academic subjects through English.

Keywords: self-regulated learning; bilingual education; science learning; activity theory; sociocultural theory;

\section{Introduction}

Academic learning presents a significant challenge for students when they transit from one learning environment to another, especially when they have to shift the medium of instruction from mother tongue to a second or foreign language in many bilingual education contexts (e.g., Pessoa, Miller, and Kaufer 2014; Zhan and Wan 2015; Hu and Gao in press). In response to such linguistic challenges, these students may need to develop the required capacity and skills and become autonomous learners who can regulate and enhance learning of language and academic 
content beyond the classroom. This draws attention to the promotion of bilingual students' selfregulated learning defined in terms of metacognitive processes including paying attention, planning, obtaining and using resources, organizing, implementing plans, orchestrating strategy use, monitoring and evaluating (Gao 2007; Oxford 2011; Teng and Zhang 2016). Since it is believed that self-regulated learners learn more and better (Pintrich 2000; Zimmerman 2000), self-regulated learning has attracted much research attention for decades. In the last few decades, researchers have examined self-regulated learning processes such as planning (e.g., Kellogg 1987), organizing (e.g., Bråten and Strømsø 2003), monitoring (e.g., Fadlelmula 2010) and evaluating (e.g., Fitzgerald 1987). In light of recent broadening of sociocultural perspectives on language learning (e.g. Lantolf 2006; Gao 2008, 2010), researchers have contended that it is important to explore the mental process situated within particular sociocultural communities. For this reason, a number of studies have explored the notions of co-regulation or socially shared regulation in learning and have focused on groups' coordination of learning during a shared activity (Panadero and Järvelä 2015). Studies have also examined individual learners' selfregulated learning as researchers view learning as a process involving appropriation of various material artefacts and discursive resources, as mediated by contextual conditions and social agents (e.g., Lantolf 2006; Vygotsky, 1978). While many relevant studies have been conducted to explore self-regulated strategic language learning (e.g., Lei 2008), very little effort seems to have been made in bilingual learning contexts where both language and subject content are the goals of learning. In such contexts, learners may encounter different challenges of using resources to mediate the self-regulated learning. To further enhance the understanding of selfregulated learning, this study draws upon the sociocultural theory to explore the way individual bilingual students appropriate resources when learning academic subjects in Hong Kong, when 
English, as an additional language, becomes both a learning goal and medium for learning. The study addressed the following research question:

How do bilingual students appropriate resources for self-regulated learning of academic subject content through English?

\section{Literature review}

\section{Self-regulated learning}

Given the belief that self-regulated learning is closely associated with effective learning, researchers have investigated self-regulated learning in various subject areas, such as science (e.g., Moos and Azevedo 2008) and language (e.g., Spörer and Schünemann 2014). Relevant studies have developed instruments to measure self-regulated learning strategies (e.g., Teng and Zhang 2016), identified relationships between self-regulated learning strategy use and variables like learning beliefs and learning outcomes (e.g., Law, Chan, and Sachs 2008) and have explored changes in self-regulated learning processes across time, in different learning environments and for different learning purposes (Coiro and Dobler 2007; Linderholm and van den Broek 2002). Researchers have also identified differences and similarities among learners in terms of selfregulated learning strategy use (e.g., Goldma et al. 2012) and have examined teachers' perceptions and instructional practices with regard to self-regulated learning (e.g., Lau 2013), besides having developed effective pedagogy to promote self-regulated learning (e.g., Teng and Zhang 2016; Schraw, Crippen, and Hartley 2006). Zimmerman and Schunk (2011) summarize four historic groups of self-regulated learning studies: metacognitive and cognitive enhancement which highlight teacher support to enhance strategy use; social and motivational processes that focus on the motivational outcomes influenced by social communities; behavioral and cognitive- 
behavioral processes of self-regulation; and Vygotsky socio-cultural perspective that highlights the mediation of contextual resources in mental development. However, research investigating self-regulated learning from Vygotsky socio-cultural perspective did not emerge until recent years, when researchers realized the importance of considering learners' discourse community to develop a full understanding of mental processes(e.g., Kang and Pyun 2013; Lantolf and Thorne 2006; Prior 2006).

\section{Sociocultural theory and resource utilization for learning}

The socio-cultural theory highlights the mediation of contextual resources in mental development. From a socio-cultural perspective, self-regulated strategic learning is defined as, 'a learner's socially mediated plan or action to meet a goal' (Oxford and Schramm 2007, 48). In this goal-meeting process, Vygotsky's idea of mediation is the key and artefacts including tools (e.g., a saw) and signs (e.g., language) are highlighted as important resources for human beings to mediate their relationships with others and the world (Lantolf 2006; Vygotsky 1978). Drawing on this notion, Engeström (Engeström 1999; 1987) developed an activity system, in which the mediating resources are expanded to artefact, community (a social group that undertakes the same actions with the same goals), rules (e.g., time and academic requirements) and division of labor (e.g., roles played and power relationships in the community) (Figure 1). Together with the artefact mediators, these mediators interact with each other when acting upon the subject's activity, from which the outcomes of the activity emerge (Engeström 2001; Yu and Lee 2016).

Conceptualization of the activity system has helped researchers gain insights into language learners' strategic use of mediating resources for self-regulated learning or strategy use as mediated by resources. (e.g., Lei, 2008; Liu, 2015; Hu and Gao in press). Through the lens of the activity theory, Lei's (2008) study on Chinese university students' writing strategy use 
revealed that the participants had used various resource-mediated strategies for writing. For example, they use internet as a resource to search for information and words that are useful for the writing. Lei (2016) further identified that both skilled and less skilled student writers use artefacts (literary works, the Internet, L2, L1, writing exercises, text already produced and outlines), rules (rhetoric, time, good writing, criteria, exam rules), community (teachers and peers) and roles (English majors) to mediate writing. However, skilled student writers were found to have assumed different roles and approached different social agents for help while less skilled student writers did not do that. In her study, skilled student writers approached social agents other than teachers and peers for help and they regarded themselves as authors, assuming responsibility for the writing process. In contrast, less skilled writers rarely approached social agents other than teachers and peers and considered themselves as someone who simply did the writing task. While Lei’s (2008; 2016) studies investigated resource-mediated strategies for language learning, Liu's (2015) study compared the resource-mediated strategies used by Chinese students in language learning and a bilingual academic learning context. The study found that the students adopted different strategies as they were mediated by institutional requirements and socio-cultural values, peers preparing for tests and teachers preparing students for the tests.

Despite the importance of contextual mediation, only a few have interpreted selfregulated learning from socio-cultural perspectives. No research has compared high- and underachievers in terms of their use of socio-cultural resources in a bilingual academic learning context. As it is believed that we might be able to enhance underachievers' success record by teaching them what high achievers do and expanding their strategy repertoire (Rubin 1975; Griffiths 2015), this study uses the activity theory as the framework to explore bilingual students' 
appropriation of resources for self-regulated learning of academic subject content, comparing the resource-mediated strategies used by high achievers and underachievers. As indicated in Figure 1, interactions among the four resources used for mediation (i.e., artefact, rules, community and role) facilitate self-regulated learning and its outcome.

\section{The inquiry}

The study was conducted to examine bilingual students' learning of Integrated Science (IS) taught with English as the medium of instruction (EMI) in a Hong Kong secondary school; English is popularly used as the medium of instruction for science-related subjects in Hong Kong (“SSP Profiles 2016/2017” 2016) as well as many other countries (Dearden 2014). The curriculum of Integrated Science in the school follows science syllabus prepared by the education department of Hong Kong, covering topics such as introduction to science, living things, cells and human reproduction, energy, solvent water, matter as particles, etc. The first year of secondary schools in Hong Kong is a transitional year in the sense that bilingual students move to an unfamiliar learning environment with new teachers, new schoolmates and different academic requirements. During the year, most also need to transit from learning through L1 (Chinese) to that through L2 (English) as medium of instruction. For the learning of IS subjects, they are required to read textbooks and learning materials written in English, to take notes in English, to learn subject knowledge through teachers' presentations in English, and to do assignments and take examinations in English, which can be quite challenging for these bilingual students.

\section{Participants}

With help from teachers of Secondary 1 (Grade 7) IS class, six high achievers and six underachievers in both English and IS were recruited for the inquiry. Three high achievers and 
three underachievers were at the end of their Secondary 1 (S1) studies at the time when the study was conducted, while the rest were at the beginning of S1. All of them were 12 or 13 years old. The medium of instruction for content subjects in their primary schools was Chinese, mother tongue of all of them. They had attended English classes in primary school but did not learn any language other than English and Chinese. The students were selected based on the latest examination results. The high achievers were among the top 10 out of 120 in Grade 7 and the underachievers were among the bottom 10. A consent form was given to the participants and their parents, explaining the goal of the research. They well understood that the data they provided would be kept strictly confidential and will be used for research purpose only, and that participation or non-participation in the study would not affect participants' academic studies at all. All the 12 students participated in the study voluntarily. The profile of the participants is presented in Table 1.

Table 1. Profile of participants ( $n=12)$

\begin{tabular}{|l|l|l|l|}
\hline Groups & Name (pseudonyms) & Gender & Time of participation \\
\hline High achievers & Katty & Female & Beginning of S1 \\
& Joey & Female & Beginning of S1 \\
& Daniel & Male & Beginning of S1 \\
& Allison & Female & End of S1 \\
& April & Female & End of S1 \\
& Amy & Female & End of S1 \\
\hline Underachievers & Cindy & Female & Beginning of S1 \\
& Frankie & Male & Beginning of S1 \\
& Thomas & Male & Beginning of S1 \\
\hline
\end{tabular}




\begin{tabular}{|l|l|l|l|}
\hline & Tracy & Female & End of S1 \\
Helen & Female & End of S1 \\
Jessica & Female & End of S1 \\
\hline
\end{tabular}

\section{Data collection and analysis}

Drawing upon Oxford and Schramm's (2007) definition of self-regulated strategic learning, we collected multiple data on students' socially mediated plans or actions, both in and off class, for learning IS. The data were collected through conducting focus-group interviews, semi-structured individual interviews, stimulated recalls and lesson observation. In the process, we also collected related learning materials and assignments. Data were collected in two waves. In the first wave, we conducted one focus group interview with three high achievers (Allison, April and Amy), one focus group interview with two underachievers (Helen and Jessica) and one individual interview with an underachiever (Tracy). The data collected in this wave prepared us for the next wave of data collection. In the second wave, we conducted lesson observation, stimulated recall and semi-structured interviews, besides collecting learning materials and assignments from six high achievers and underachievers who had just started their S1 studies. We also observed the six students' behaviors in IS lessons, during which field notes on how they appropriated learning resources were taken. The students' learning behaviours, such as taking notes and seeking help from classmates, were observed. The actions they took when they had difficulties were paid particular attention. After the lessons, we collected their assignments and the notebooks where students themselves took notes in the learning process. Then each student participant was interviewed in the first language about the IS learning experience. General questions about students' IS learning inside and out of classes were asked first, including 'what do you think of 
IS learning so far' and 'what do you normally do when you have difficulties during IS learning'. Students were allowed to freely come up with strategies and resources they had used first. When they mentioned the use of a resource, we asked further questions about how often and why they used it. We also listed the resources that they did not mention and asked them how often they had used the resources, and why or why not. After the interviews, stimulated recalls were conducted with collected artefacts such as assignments and learning notebooks as the stimuli. In the stimulated recall, the students were asked to recall what difficulties they had faced and how they responded to these in the learning process. All the interviews and stimulated recalls were conducted in students' mother tongue (Chinese). Both semi-structured interviews and stimulated recalls were audio-taped and transcribed verbatim in Chinese by a research assistant, and double checked by another. The transcribed interviews and stimulated recalls, together with the field notes taken in the lessons, students' notes, and written assignments, were analyzed in triangulation to enhance the rigor of analysis.

For analysis, the data were read deductively and coded into the four categories of resources (i.e., artefact, rule, community and role) in the framework of the activity theory. To operationalize the theory for analysis, artefact refers to the tools and signs that bilingual students can use for learning, such as dictionary (tool) and language (sign). Rules here refer to the criteria, requirements, or regulations related to bilingual students' learning. Community refers to social groups that bilingual students can associate with inside or outside schools. Role here indicates how bilingual students divide their labor during the process of learning (Lei 2008; Lei 2016; Yu and Lee 2016). Then the data were read again inductively to identify the sub-categories of mediating resources, such as 'L1', 'L2', 'textbook', 'dictionary', etc. Comparison was constantly made among categories as well as across data sources and participants. The first author and a 
trained research assistant coded the data collected from one participant independently and compared the coding results, which led to an inter-rater agreement of $80 \%$. Discrepancies were resolved through discussions with the second author before we coded the rest of the data and finalized the categories of findings (Corbin and Strauss 2014).

\section{Findings}

Drawing on the activity theory, the study identified how bilingual students appropriate resources strategically for self-regulated learning of science in Hong Kong. Findings show that our participants used all the four categories of resource-mediated strategies (i.e., artefact-mediated strategies, rule-mediated strategies, community-mediated strategies and role-mediated strategies) (Engeström 2001; Yu and Lee 2016). The high achievers and the underachievers were also found to have displayed different patterns of strategy use for appropriating resources. The ways the two groups of participants used each strategy and the reasons thereof are elaborated in the following sections.

\section{Artefact-mediated strategies}

The participants, especially the high achievers, were found to have strategically used artefacts, including textbooks, notes, dictionary, symbols, L1 and L2 as resources to facilitate selfregulated learning. Such strategic use of artefacts can be further categorized into tool-mediated strategies (i.e. participants' utilization of physical learning resources) and sign-mediated strategies (i.e. participants’ strategic reliance on symbols, L1 and L2 as learning resources) (Lei 2008).

\section{Tool-mediated strategies}

The participants in this inquiry had largely used tools including textbooks, notebooks, dictionaries and internet for self-regulated learning of IS. The data suggest that high achievers 
often referred to textbooks and notes when they had difficulties related to either language or content. They recycled sentence patterns in the textbooks and notes when completing written assignments. They also infer difficult words' meanings with the help of textbooks and notes as follows:

Vocabulary like “reptile”, “amphibian” are difficult to remember. I often mix them up if I don’t have the textbook to refer to. But once I check the textbook, I recognize the meaning. (April, focus group)

In contrast, the underachievers also used textbooks and notes less often. As found in the interviews, they had difficulties in using the textbooks or notes due to lack of ability to locate useful information and low English proficiency. For example, Frankie was not sure whether the sentences he found from the textbooks could be used to answer questions when doing exercises:

About this question, I just wrote down what was relevant to the question. As I knew some words in the question, I just looked for the words [from the textbook] and wrote down [the sentences]. (Frankie, stimulated recall)

As can be seen in the extract, he copied sentences only if they contained the words that appeared in the questions. In other words, he did not engage with these sentences in a meaningful manner to facilitate the learning. Likewise, underachievers referred to the textbook or notes only when they could locate the relevant information easily. They were also less willing to use notes for learning because they did not know whether particular notes would be useful:

In Form 1, no one told us to write notes and our lesson notebook wouldn't be checked. I thought exam just depended on the content in the textbook. But now, I jot down notes during the lessons. [I understand that] teacher tells us some knowledge beyond the textbook. (Tracy, interview) 
It seems that Tracy was not particularly motivated to write down notes in the first place and for this reason, she had little idea of what to use the notes for. Only at the instigation of teachers, she started to know that the contents included in the notes would be involved in the examinations and to appreciate the importance of note-taking and using them as a resource for self-regulated learning.

Apart from textbooks and notes, the high achievers used dictionary or internet frequently in the self-regulated learning process (Lei 2008). In the focus group interview, Amy and Allison reported that they had used dictionary more often than other resources because dictionary is convenient to use. Furthermore, they mentioned that they did not look up every single word in the dictionary and consulted dictionary only for keywords that affect understanding:

... before this lesson was taught, I browsed it. I found it somewhat interesting. [I wondered] what was in it. [There were] these words, such as vertebrates, invertebrates, etc...normally I just browse it. Sometimes I don't know the words. It doesn't matter. Sometimes I search for them on the internet if I really want to know [their meaning]. (Daniel, stimulated recall)

As can be seen in the excerpt above, Daniel had a clear purpose when looking up words in the dictionary as he wanted to familiarize himself with the lesson's main idea by understanding keywords like vertebrates and invertebrates. This shows how goals mediate the strategic efforts that participants put in self-regulated learning (e.g. Liu 2015).

In comparison with the high achievers, the underachievers do not regard dictionary as a preferred learning resource because they do not feel that they can better understand sentences by looking up words in it. Considering they had to learn the subject content in L2, they probably had too many unknown words that they needed to look up in the dictionary. In addition, they 
were unable to use dictionary effectively since they found it difficult to choose the right one from various meanings of a word presented in the dictionary:

I looked it up in the dictionary, but it showed other meanings of the word in the dictionary. It was not related to IS. It didn’t feel like an IS meaning anyhow. (Cindy, stimulated recall)

As shown in the excerpt above, Cindy was confused by the non-technical meaning shown in the dictionary which she assumed to be technical. She believed that the dictionary did not give her the meaning suitable for the scientific language, in the particular context. As such misunderstandings accumulated, she stopped using the dictionary. Similarly, Tracy also believed that dictionary could not help her to identify the scientific meaning of a word:

For English, I check the vocabulary in the dictionary. But for Science, I probably have problems in answering the question if I didn't pay attention during the lesson. Because even though I know the Chinese meaning of the word, my writing is usually not accurate. They are all technical terms. And I usually ask my cousin for help. (Tracy, interview)

Negative experiences of using tools, including dictionaries, discouraged these participants from using them. Such negative experiences might have been caused by the fact that the underachievers did not even know how to use a dictionary because they did not know 'how to use the Chinese words to look up for the corresponding English words in the dictionary'. (Frankie, stimulated recall). This draws attention to the participants' use of L1 in learning subject content in L2 (i.e. English) (e.g. Lei 2008).

\section{Sign-mediated strategies}

Apart from tools, participant students used signs to mediate the self-regulated learning process. The sign-mediated strategies highlight students' strategic reliance on symbols, L1 and L2 as learning resources. In the inquiry, the high achievers were found to have often used L1 to 
mediate self-regulated learning (Lei 2016; Yu and Lee 2016). They used L1 to understand assignment questions and IS content. For instance, Daniel reflected on English notes' meanings in Chinese to make sure that he had understood the notes properly. Similarly, after seeking help from her classmates, Katty often translated the provided information into Chinese to see whether it made sense. She also translated assignments' writing requirements into Chinese if she did not understand them. She explained that using L1 to understand the writing requirements was important, as it was lack of clarity about writing requirements that made it difficult for her to complete written assignments:

Sometimes you don't know what to write, just because you don't know what it asks you to write. In other words, you know what to write [when you understand the requirements], but you just don’t understand what it asks you to do. [When this happens,] just translate it into Chinese and see if you understand. If you don’t understand, you can ask the teacher. (Katty, interview)

In contrast, the underachievers often did not use L1 strategically to mediate self-regulated learning of IS. Although they had to struggle more with L2, they were reluctant to rely on L1 to better understand IS content because they were not sure whether L1 could be a useful resource for learning:

I do not usually translate the whole sentence, because if the translation isn’t correct, it will mislead my understanding. (Cindy, interview)

This fear of wrong translation probably deprived the underachievers of a valuable resource that could have effectively mediated their self-regulated learning of IS. Instead of relying on what they were strong at, they depended on L2 in the learning process. As captured in the inquiry, both the high achievers and the underachievers knew the important role L2 
proficiency plays in learning science content and scientific language. They knew that they might fail to complete the assignments if they did not understand the writing requirements due to low L2 proficiency. Allison noted that she knew how to do the science assignments once she understood the English. Daniel highlighted the importance of English grammar and vocabulary when he talked about L2 proficiency and IS learning:

If your grammar and vocabulary are not good enough, you may not understand what the teacher is talking about. Of course, if there is only one word that you don't understand, you can ask your classmates, but you still need to learn more grammar and vocabulary to make it up. (Daniel, interview)

The underachievers shared a very similar view with regard to the role of L2 proficiency in the learning of IS subject. They also believed that English vocabulary was essential for IS learning. Thomas explained the connection between English proficiency and academic learning as follows:

[English is] very important [to IS learning], as all [the IS contents] are [taught in] English. If you don't know English, you are not able to do the assignments. (Thomas, interview)

Realizing the importance of L2 proficiency, both high achievers and underachievers believe they should learn more of English for the learning of IS. For example, Thomas, an underachiever, highlighted the use of grammar exercises as an important strategy to improve his English. Similarly, the high achievers also thought more exposure to English to be an effective way. For example, Amy said she read more books to help her learn English, especially fiction. She explained that she could learn adjectives when reading fiction. Though scientific terms are not used in these books, she still thought it helped her to learn English better. And once she had a 
better command of English, she thought she could learn IS better. Joey described how she undertook strategic efforts to improve her English as follows:

I like reading English books and I always memorize the pronunciation of new words. I don't have problem with these words, because they appeared in the books I have read before. I can spell them according to their pronunciation. Take "antelopes" for example, I write down "an", and then "te", and then "lopes" ... I usually talk to foreigners [in English]. A lot of my relatives are foreigners. I also talk to my dad in English every day, and that makes it easy for me to spell the words. (Joey, stimulated recall)

Likewise, the underachievers (e.g. Helen, Jessica and Tracy) also thought attending tutorial classes after school are useful for improving English. They thought tutorial classes were especially useful for those who could not follow the teachers and were too shy to ask questions in class. It seems that both the high achievers and the underachievers had a consensus that efforts should be made to improve L2 proficiency for the learning of IS.

Previous research has revealed that learners regulate memorization with symbols (e.g., Fadlelmula 2010). The high achievers were found in the inquiry to have used symbols such as brackets, asterisk and various colors, to regulate learning of subject content knowledge. The underachievers used symbols less and displayed different patterns of symbol usage in comparison with the high achievers. Figure 2 and Figure 3 show how the higher achievers and the underachievers used symbols differently to mediate their learning.

The two figures are notes on the same information taken by a high achiever, Joey, and an underachiever, Thomas. As indicated in Figure 2, Joey used various symbols (e.g., ‘*', ' $\rightarrow$ ’) and different colours to highlight, differentiate, categorize and systematize the notes. However, the underachievers like Thomas (Figure 3) seldom used symbols or colours to reorganize the notes.

\section{Rule-mediated strategies}


Like the learning of other subjects in other contexts, the participants' self-regulated learning of IS was found to be mediated by appropriation of rules, such as evaluation criteria (Yu and Lee 2016) and time constraints (Lei 2008). This section presents how these rules mediated the participants' self-regulated learning.

\section{Evaluation criteria-mediated strategies}

The high achievers' self-regulated learning was profoundly mediated by evaluation criteria. They acquired and used resources that were useful for them to achieve better performance when writing assignments and taking examinations. They usually focused on learning and memorizing content and languages that were to be evaluated.

The high achievers stressed in the interviews that they had to use key terms in IS accurately to ensure their grades would not suffer any deduction. They always followed this evaluation requirement closely when writing assignments or undertaking examinations. They also wrote exact number of possible answers as required in the questions even when they knew more correct answers, again reflecting the mediation of evaluation criteria. For example, Joey recalled how she wrote for an assignment on external features of animals as follows:

I wrote down "it has feathers. It has a beak", as these two sentences had met the requirements of the question...[although] the parrot has many other features. It has legs, wings, feathers, beaks, lay[s] eggs. But the question only asked me to put down two. (Joey, stimulated recall)

Consequently, she stated only two features, to fulfil the task requirements. In addition to such adherence to task requirements, the high achievers were also highly selective in choosing subject knowledge and the language used in evaluation. They memorized only grammar and sentence patterns that helped improve score in the examination. The high achievers like Daniel 
memorized the notes' contents even though he could refer to the notes when writing assignments because he memorized them for the exams:

Normally I review them [the notes] ... as sometimes there are tests or quizzes ... [to review] means to memorize. (Daniel, interview)

The high achievers understood that their learning is evaluated through assignments and examinations, which cover the content and language in the notes provided by the teacher apart from those in the textbooks. Therefore, they also considered notes an important resource to be used in the self-regulated learning process:

Much information the teacher gives orally is covered in the examinations...sometimes he doesn't write it down, but sometimes he provides orally. If you jot it down and memorize, you will get scores. If you don't, but only memorize what is in the textbook, you won't know [what to write in the examinations]. (Katty, interview)

Since the rules (evaluation criteria) were found to have mediated the participants' use of artefact (notes) as outlined in the extracts above, it is safe to conclude that the participants' appropriation of learning resources such as notes for self-regulated learning resulted from a combined mediation of rules and artefacts. There is evidence that shows interaction between evaluation criteria and other artefacts like dictionary or internet which mediate the high achievers' strategy use. This is reflected in the aforementioned fact that the high achievers (e.g. April) often used dictionary or internet to learn meanings of keywords that help improve scores in the evaluation.

In contrast, the underachievers used fewer evaluation criteria to mediate appropriation of resources for self-regulated learning. Like the high achievers, the underachievers too sometimes wrote assignments according to the evaluation criteria. For example, Helen reported in the 
interview that grammar could be ignored in the writing, because writing down the main points was sufficient for her to get scores. The underachievers were also less aware of the criteria used to assess their learning in IS. They tended to apply the criteria set for learning in primary schools to learning in secondary schools. For example, when required to write classification reports, naming things under categories, Thomas, Cindy and Frankie only named the categories, like they used to do in primary schools. They were not aware that the task had different requirements in secondary school.

\section{Time-mediated strategies}

Echoing the findings reported in extant research which found high achievers' self-regulated learning was mediated by time (Lei, 2008), evidence in this study also shows the students' use of time-mediated strategies. For example, due to the time constraints, the high achievers became selective when taking notes. They only took notes on things that were new, yet to be understood, or important to them. The study also found that the underachievers' self-regulated learning was mediated by time. Due to low English proficiency, underachievers usually need more time to take notes. Nonetheless, the limited time available during the lessons requires a fast speed of note taking, which leads to these participants' failure to take important notes. The limited lesson time apparently also prevents students from asking their classmates or teachers questions. For this reason, underachievers like Jessica consider seeking complementary support after the class. She said,

For the students who can't follow, the teachers can give extra tutoring. For example, we have a group of thirty some students. We have classes for supplementary schooling. [In the classes], the teacher asks the students one by one about the difficulties they have in the given lesson. (Jessica, focused group interview) 
Due to the limited time, the underachievers were not able to review and memorize everything taught even though some of them tried hard. For example, Cindy confessed that she was seldom able to memorize notes taken in IS lessons. She explained that she was overwhelmed by the large number of new contents and words. In addition, the limited time did not allow her to appreciate the answers provided by her classmates, either. When completing written assignments, she just wrote down what her classmates told her without understanding it because of the pressing deadline for submission.

The underachievers experienced similar time-related challenges in the examinations. According to Thomas, when he has problems in understanding a question or writing the answer to the question, he skips it and moves on to the next. He explained 'otherwise I won't have enough time to answer the last question' (Thomas, interview). While acknowledging the importance of some strategies (e.g., reviewing, memorizing, re-reading the difficult texts, etc.), the underachievers gave up using them because of the time constraints. It seems that time constraints do not make the underachieves strategically selective like the high achievers; instead they 'dodge' difficult questions in the self-regulated learning process.

\section{Community-mediated strategies}

Appropriation of resources for self-regulated learning of IS by the participants in the inquiry was found to have been mediated by the broad society and immediate school communities. Various social agents such as teachers, peers and members of family facilitated the participants' selfregulated learning.

\section{School community-mediated strategies}

Teachers and classmates are the key members of a community inside a school (Lei 2008; Yu and Lee 2016). The high achievers reported having asked their teachers or classmates for help 
sometimes when they had difficulties in writing assignments, when the use of artefact-mediated strategies failed to help them solve the problems or when the problems could be solved faster by asking teachers or classmates than by using artefact-mediated strategies. For example, Joey said:

I ask my classmates [if I have problems]. If they don’t know either, I ask my teacher or some other people who know [the answer] ... Actually, you won't have many problems if you review the textbooks and the notes. (Joey, interview)

As can be seen in the extract above, Joey might have viewed textbooks and notes as the most important learning resource. She asks her classmates when she cannot find the answer in the textbooks or notes, and then asks her teacher if her classmates cannot help her solve the problem. Katty said she does the same, normally when having problems while reading the assignment requirements. Slightly different, Katty first used L1-mediated strategies for the reading. She would then ask the teacher or the classmates if she still did not understand after using L1-mediated strategies. Similarly, April relied on artefacts rather than asking teachers or classmates on encountering difficult words. In the interview, she responded that she always looks up the difficult words in the dictionary or refer to the notes provided by the teacher. Amy and Allison also reported that they used dictionary strategies more often than asking people for working out the meaning of difficult words. As mentioned earlier, they found using dictionary more convenient.

Like the high achievers, the underachievers too regarded classmates as an important resource. Although they were in the very beginning of Year 1 study, they had classmates who were from the same primary schools and had made some new friends in the training camp before the starting of the Secondary 1 school year. As Tracy recalled in the interview, 'for the sake of convenience', they could ask 'classmates for help when [they] had homework problems'. Frankie 
said he normally asks classmates when he encounters difficult words. Even when he is not with his classmates after school, he does not use other strategies but asks his classmates when he meets them. Likewise, Jessica indicated in the group interview that she preferred asking classmates to other methods because it was more convenient. Society-mediated strategies

Society-mediated strategy refers to the participants' appropriation of social resources outside school (Lei 2008), such as family members and friends, for self-regulated learning of IS. In the inquiry, some of the participants were found to have used social resources outside school while others did not. The interview data reveal that the high achievers decided whether to use social resources or not according to the availability and usefulness of the resources. For example, Katty usually asked her mother when doing assignments at home if the problems could not be solved after she had checked the notes or textbooks. She said her mother could help her understand assignment questions written in English but she could not help her complete these assignments. Nevertheless, she preferred asking her mother for help rather than her classmates because it was convenient to do so at home:

My mom understands [the questions] better. She knows more [than my classmates] ... Sometimes they [my classmates] may not know [the correct one], but just give me a wrong answer. (Katty, interview)

In a similar vein, Joey used her family resources to improve her English proficiency. On one hand, she attached great importance to English proficiency in learning science subject knowledge. On the other hand, she thought her family members could help her since they had high English proficiency and were often available when they were needed. In contrast, Daniel seldom asked his parents when having problems with learning science subject knowledge 
because 'they don't have much time' (Daniel, interview). Daniel could not access social resources easily and for this reason relied more on artefacts. Indeed, he solved most learning problems by checking notes and consulting dictionary. Similarly, Allison said she did not ask her family members because they did not have the relevant knowledge. For this reason, she used other types of social resources such as friends or artefacts such as dictionary.

Similar to the high achievers, the underachievers used social resources in different ways. Cindy, Helen and Tracy used social resources quite often. Helen often asked her private tutor for help in the learning process because she was able to meet her tutor thrice a week. Tracy considered her cousin as an important resource for learning science subject knowledge at home. It seems that easy access was one of the most important reasons for these participants to use particular social resources. It must be noted that not all underachievers used social resources frequently. Jessica reported having asked her elder sister for help but she found that her classmates were more helpful in enabling her to overcome learning challenges. Thomas never mentioned using social resources to solve problems in the learning process. It is also important to note that the underachievers did not always make their decisions on whether to use social resources based on the usefulness of the resources. For example, Cindy mentioned asking her elder sister for help several times though her elder sister failed to help her most of the time:

[The meaning of the word found in the dictionary] did not look like a scientific term, so I asked my elder sister, but she didn’t know. And then I asked my classmates. They didn’t know either. (Cindy, stimulated recall)

Cindy's attempts to get help from different sources such as dictionary, her elder sister and classmates indicated that she did try to use a variety of resources. However, that she tried 
resources that she knew were not useful also suggests that she did not have many resources to choose from when overcoming learning challenges.

\section{Role-mediated strategies}

The role students play in the process of learning is also an important resource that mediates utilization of available learning resources (Lei 2008). In EMI contexts like Hong Kong, the learning of EMI subjects is expected to achieve dual goals - language and subject contents (Lo 2015), and thus language students understandably play dual roles in EMI subject learning language learners and subject content learners.

In this study, both the high achievers and the underachievers tended to view themselves as both subject content learners and language learners. Students like Daniel, Katty and Frankie thought the process of learning science subject knowledge is also a process of learning English, due to the use of English as the medium of instruction. At the same time, they perceive themselves as subject content learners more than English language learners when learning science in the medium of English. Such role awareness motivates them to learn and use the English language, useful for science learning specially when reading science texts and writing science assignments. As mentioned earlier, the high achievers looked up words in the dictionary only if they affect understanding of science texts or the scores in IS examinations (see example of Amy, Allison and Katty in the section "Dictionary/internet-mediated strategies” and April in the section "Evaluation criteria-mediated strategies”). They also tended to memorize key science subject content and language covered in IS examinations (see example of Katty in the section “Evaluation criteria-mediated strategies”). They were concerned about the accuracy of language use only when it affected IS subject examination results (see example of Helen in the section 
“Evaluation criteria-mediated strategies”). This shows the interaction between the IS learner role the students play and the rule-mediated strategies they use.

\section{Discussion}

While most of previous research on self-regulated learning has explored cognitive and metacognitive processes of planning, organizing, monitoring and evaluating (e.g., Bråten and Strømsø 2003; Fadlelmula 2010; Fitzgerald 1987), the current study draws upon the activity theory to look into bilingual students' self-regulated learning of subject content, focusing on their strategy use in using resources.

Echoing previous research (Engeström 1999; Engeström 1987; Lei 2008; Yu and Lee 2016), the study revealed how bilingual students' strategy use in learning science in the medium of English is mediated by four categories of resources: artefacts, rules, communities and roles. In comparison with previous research (e.g., Lei 2008), a wide range of social agents including friends, classmates, members of family and private tutors ('community') are identified to have mediated bilingual students’ learning outside school (e.g. Panadero and Järvelä 2015). Besides, unlike in a 'learning to write' context, where student writers play the role of either language learners or authors (e.g., Lei 2008), bilingual students examined in this study see themselves as both language learners and subject content learners. These two roles, especially the role of subject content learners, were found to have greatly mediated learners' strategy use. There is evidence showing that the four categories of resources interact with each other while mediating learners' utilization of resources for self-regulated learning of science subject knowledge in the medium of English. For example, use of the strategy 'consulting the dictionary only for the keywords that would affect students' understanding of subject content' reflects the interaction between artefact-mediated strategies and role-mediated strategies (see 'tool-mediated strategies' 
for evidence). As shown in the findings, students like Cindy stopped looking up words in the dictionary when they found doing that did not help them understand the subject content, even though it could help them develop vocabulary. The results are also indicative of the interaction between the use of artefact-mediated strategies and self-perceptions as superior IS learners in the self-regulated learning process. The fact that a student like Tracy did not take notes until she knew that taking notes would affect her examination scores is also suggestive of the interaction between artefact-mediated strategies and rule-mediated strategies. The interaction between artefact-mediated strategies and community-mediated strategies is shown by the evidence that students like Katty often translated the information provided by her classmates into Chinese to see whether it made sense. As discussed in the previous section, the role-mediated strategies also interacted with rule-mediated strategies.

As in previous research (Lei 2016), this study also found that sources of mediation affect both the high achievers and the underachievers. The current study further reveals that the two groups of bilingual students were different in terms of preferences and patterns of using resources. For example, the high achievers preferred to use artefacts such as textbooks, notes, dictionary, L1, symbols, etc., while the underachievers used much less of these resources but preferred community resources. While previous studies found that skilled learners used timemediated strategies often (e.g., Lei 2008), the current study indicated that time, as a rule resource, understandably affected the underachievers more.

Besides, the study also revealed the reasons for the differences. Evidence was found showing that the differences were due to the participants' perceived usefulness of the resources, ability of using the resources and availability to the resources. The students did not use the strategies (e.g., taking notes) until they found them important (see Tracy's interview responses in 
the section 'textbook/note-mediated strategies'). Similarly, it was the perceived importance of the role English played in IS learning that made both high- and under- achievers used L2mediated strategies. Availability of the resources was the second reason why the students used or did not use them to mediate strategy use. Students like Amy and Allison used dictionary most frequently when they had problems with understanding the language, because the dictionary was always available. The ability of using the resources also explained the use or non-use of resource-mediated strategies. Sometimes, students lacked techniques for using particular resources. This is reflected in Frankie's stimulated recall response, explaining why he seldom used dictionary. In other cases, the students lacked L2 proficiency for using particular resources, such as referring to notes and translating English to Chinese.

Based on the findings, the proposed activity system was modified (Figure 4), which could be used as a model for further inquiries on bilingual students' self-regulated learning of subject content and language (e.g., Liaw, Huang, and Chen 2007).

\section{Conclusion}

This study investigated bilingual students' self-regulated appropriation of resources for academic learning in an EMI context in light of the activity theory. Categories and sub-categories of resource-mediated strategies were identified. Similarities and differences between high achievers and underachievers were found, regarding their self-regulated appropriation of resources. The reasons beneath and the interaction among resource-mediated strategies were also identified. As is the case with all qualitative research, the findings of this study cannot be generalized to a larger population. However, the possibility revealed in the study in terms of how the learning strategy use of bilingual learners is mediated by contextual resources contributes to a better 
understanding of self-regulated learning from a socio-cultural perspective (e.g. Gao 2007; Teng and Zhang 2016).

The differences between the high achievers and underachievers regarding use of mediating resources as well as the reasons beneath have important implications for pedagogical practices. It is believed that we might be able to enhance underachievers' performance by teaching them what high achievers do and expanding their strategy repertoire (Rubin 1975; Gao 2010; Griffiths 2015). However, we argue that simply asking underachievers to use the resourcemediated strategies used by high achievers may not help, because underachievers may fail to use the strategies because of multiple reasons, as indicated in this study. We thus suggest teachers find out the reasons first and provide pedagogical support accordingly. For example, the learners did not use some useful resources simply because those resources were not available to them. We therefore suggest teachers provide as many resources as possible to the learners, especially the underachievers. For instance, considering the underachievers' low L2 proficiency, teachers should reduce the number of notes provided orally; they can instead write down the important notes and give more time to learners for copying the notes. Teachers should also spend more time with underachievers as an accessible community resource that learners can seek help from when they have difficulties in the learning process. As learners may not understand the importance of some resources or have ability to use some of the provided resources, teachers need to give clear instructions on why the resources are important and how they can be used. The interactions among resource-mediated strategies also imply that teaching students the strategies used by high achievers is not sufficient and the effective use of the strategies, taking into account the interactions among them is more important. For example, when encouraging students to use dictionary for difficult words, teachers may also ask students to think about the evaluation 
criteria for and the goals of EMI subject learning (e.g., Are these words important; Is English learning one of the goals; Is it as important as subject content learning).

\section{Acknowledgement:}

We would like to thank Professor Jean-Marc Dewaele and the reviewers for their constructive feedback on our work. Our work has been generously supported by Standing Committee on Language Education and Research (SCOLAR) (Hong Kong) (EDB(LE)/P\&R/EL/164/19).

\section{Notes on contributors}

Dr. Jingjing Hu is a postdoctoral fellow at the Faculty of Education, The University of Hong Kong. Her research interests include sociocultural theory, self-regulated language learning, introspective methods and language teacher education.

Dr. Xuesong (Andy) Gao recently joined the School of Education, the University of New South Wales Australia as an associate professor. His research interests including language learning strategy, international students in higher education, language teacher education and language education policy.

\section{References}

Bråten, Ivar, and Helge I. Strømsø. 2003. “A Longitudinal Think-Aloud Study of Spontaneous Strategic Processing during the Reading of Multiple Expository Texts.” Reading and Writing 16 (3): 195-218.

Coiro, Julie, and Elizabeth Dobler. 2007. “Exploring the Online Reading Comprehension Strategies Used by Sixth-Grade Skilled Readers to Search for and Locate Information on 
the Internet.” Reading Research Quarterly 42 (2): 214-57. doi:10.1598/RRQ.42.2.2.

Corbin, Juliet, and Anselm Strauss. 2014. Basics of Qualitative Research: Techniques and Procedures for Developing Grounded Theory. 4th ed. SAGE Publications.

Dearden, Julie. 2014. “English as a Medium of Instruction -- A Growing Global Phenomenon.” http://doi.org/10.1080/0013191610140107.

Engeström, Yrjö. 1987. Learning by Expanding: An Activity Theoretical Approach to Developmental Research. Helsinki: Orienta-Konsultit Oy.

—. 1999. "Activity Theory and Individual and Social Transformation.” In Perspectives on Activity Theory, edited by Yrjö Engeström, R. Miettinen, and R.-L. Punamäki, 19-38. Cambridge: Cambridge University Press.

— 2001. "Expansive Learning at Work: Toward an Activity Theoretical Reconceptualization.” Journal of Education and Work 14 (1): 133-56. doi:10.1080/13639080020028747.

Fadlelmula, Fatma K. 2010. "How a Learner Self-Regulates Reading Comprehension : A Case Study for Graduate Level Reading.” US-China Education Review 7 (10): 22-29.

Fitzgerald, Jill. 1987. “Research on Revision in Writing.” Review of Educational Research 57 (4): 481-506.

Gao, Xuesong. 2007. "Has language learning strategy research come to an end? A response to Tseng et al. (2006).” Applied Linguistics, 28(4), 615-620. doi: 10.1093/applin/amm034.

— 2008. "You had to work hard 'cause you didn't know whether you were going to wear shoes or straw sandals!” Journal of Language, Identity and Education 7(3-4):169187.doi:10.1080/15348450802237798.

— 2010. Strategic Language Learning: The Roles of Agency and Context. Bristol: 


\section{Multilingual Matters.}

Goldma, Susan R., Jason L G Braasch, Jennifer Wiley, Arthur C. Graesser, and Kamila Brodowinska. 2012. “Comprehending and Learning from Internet Sources: Processing Patterns of Better and Poorer Learners.” Reading Research Quarterly 47 (4): 356-81. doi:10.1002/RRQ.027.

Griffiths, Carol. 2015. “What Have We Learnt from ‘Good Language Learners ’?” ELT Journal 69 (4): 425-33. doi:10.1093/elt/ccv040.

$\mathrm{Hu}$, Jingjing, and Gao, Xuesong. In press. “Self-regulated strategic writing for academic studies in an English-medium-instruction context.” Language and Education. doi: 10.1080/09500782.2017.1373804

Kang, Yon-Soo, and Danielle O. Pyun. 2013. “Mediation Strategies in L2 Writing Processes: A Case Study of Two Korean Language Learners.” Language, Culture and Curriculum 26 (1): 52-67. doi:10.1080/07908318.2012.762012.

Kellogg, Ronald T. 1987. "Effects of Topic Knowledge on the Allocation of Processing Time and Cognitive Effort to Writing Processes.” Memory \& Cognition 15 (3): 256-66. doi:10.3758/BF03197724.

Lantolf, James P. 2006. “Sociocultural Theory and L2: State of the Art: State of the Art.” Studies in Second Language Acquisition 28 (1): 67-109. doi:10.1017/S0272263106060037.

Lantolf, James P., and Steven L. Thorne. 2006. Sociocultural Theory and the Genesis of Second Language Development. Oxford: Oxford University Press.

Lau, Kit L. 2013. “Chinese Language Teachers’ Perception and Implementation of SelfRegulated Learning-Based Instruction.” Teaching and Teacher Education 31 (1): 56-66. doi:10.1016/j.tate.2012.12.001. 
Law, Yin-kum, Carol K. K. Chan, and John Sachs. 2008. "Beliefs about Learning, SelfRegulated Strategies and Text Comprehension among Chinese Children.” The British Journal of Educational Psychology 78 (Pt 1): 51-73. doi:10.1348/000709907X179812.

Lei, Xiao. 2008. “Exploring a Sociocultural Approach to Writing Strategy Research: Mediated Actions in Writing Activities.” Journal of Second Language Writing 17 (4): 217-36. doi:10.1016/j.jslw.2008.04.001.

— 2016. "Understanding Writing Strategy Use from a Sociocultural Perspective: The Case of Skilled and Less Skilled Writers.” System 60. Elsevier Ltd: 105-16. doi:10.5353/th_b4308567.

Liaw, Shu S., Hsiu M. Huang, and Gwo D. Chen. 2007. “An Activity-Theoretical Approach to Investigate Learners’ Factors toward E-Learning Systems.” Computers in Human Behavior 23 (4): 1906-20. doi:10.1016/j.chb.2006.02.002.

Linderholm, Tracy, and Paul van den Broek. 2002. “The Effects of Reading Purpose and Working Memory Capacity on the Processing of Expository Text.” Journal of Educational Psychology 94 (4): 778-84. doi:10.1037//0022-0663.94.4.778.

Liu, Jie. 2015. "Reading Transition in Chinese International Students: Through the Lens of Activity System Theory.” Journal of English for Academic Purposes 17. Elsevier Ltd: 1-11. doi:10.1016/j.jeap.2014.11.004.

Lo, Yuen Y. 2015. “How Much L1 Is Too Much? Teachers’ Language Use in Response to Students’ Abilities and Classroom Interaction in Content and Language Integrated Learning.” International Journal of Bilingual Education and Bilingualism 18 (3): 270-88. doi:10.1080/13670050.2014.988112.

Moos, Daniel C., and Roger Azevedo. 2008. “Monitoring, Planning, and Self-Efficacy during 
Learning with Hypermedia: The Impact of Conceptual Scaffolds.” Computers in Human Behavior 24 (4): 1686-1706. doi:10.1016/j.chb.2007.07.001.

Oxford, Rebecca L. 2011. Teaching and Researching: Language Learning Strategies.

Oxford, Rebecca L., and K. Schramm. 2007. "Bridging the Gap between Psychological and Sociocultural Perspectives on L2 Learner Strategies.” In Language Learner Strat- Egies, edited by A. D. Cohen and E. Macaro, 47-68. Oxford, UK: Oxford University Press.

Panadero, Ernesto, and Sanna Järvelä. 2015. "Socially Shared Regulation of Learning: A Review.” European Psychologist 20 (3): 190-203. doi:10.1027/1016-9040/a000226.

Pessoa, Silvia, Ryan T. Miller, and David Kaufer. 2014. “Students’ Challenges and Development in the Transition to Academic Writing at an English-Medium University in Qatar.” IRAL International Review of Applied Linguistics in Language Teaching 52 (2): 127-56. doi:10.1515/iral-2014-0006.

Pintrich, P. 2000. “The Role of Goal Orientation in Self-Regulated Learning.” In Handbook of Self-Regulation, edited by M. Boekaerts, P. Pintrich, and M. Zeidner, 452-501. San Diego, CA: Academic Press.

Prior, Paul. 2006. “A Sociocultural Theory of Writing.” In Handbook of Writing Research, edited by S. Graham C. A. MacArthur and J. Fitzgerald, 54-66. New York: The Guilford Press.

Rubin, Joan. 1975. “What the ‘good Language Learner’ Can Teach Us.” TESOL Quarterly 9 (1): $41-51$.

Schraw, Gregory, Kent J. Crippen, and Kendall Hartley. 2006. "Promoting Self-Regulation in Science Education: Metacognition as Part of a Broader Perspective on Learning.” Research in Science Education 36 (1-2): 111-39. doi:10.1007/s11165-005-3917-8. 
Spörer, Nadine, and Nina Schünemann. 2014. "Improvements of Self-Regulation Procedures for Fifth Graders’ Reading Competence: Analyzing Effects on Reading Comprehension, Reading Strategy Performance, and Motivation for Reading." Learning and Instruction 33: 147-57. doi:10.1016/j.learninstruc.2014.05.002.

“SSP Profiles 2016/2017.” 2016. Accessed December 9. http://www.chsc.hk/ssp2016/eng/index.php.

Teng, Sophie L., and Lawrence J. Zhang. 2016. “A Questionnaire-Based Validation of Multidimensional Models of Self-Regulated Learning Strategies.” Modern Language Journal 100 (3): 674-701. doi:10.1111/modl.12339.

Vygotsky, Lev S. 1978. Mind in Society: The Development of Higher Psychological Processes. Cambridge, MA: Harvard University Press.

Yu, Shulin, and Icy Lee. 2016. “Exploring Chinese Students’ Strategy Use in a Cooperative Peer Feedback Writing Group.” System 58. Elsevier Ltd: 1-11. doi:10.1016/j.system.2016.02.005.

Zhan, Ying, and Zhi H. Wan. 2015. “College Students’ Possible L2 Self Development in an EFL Context during the Transition Year.” English Language Teaching 9 (1): 41. doi:10.5539/elt.v9n1p41.

Zimmerman, Barry J. 2000. “Attaining Self-Regulated Learning: A Social-Cognitive Perspective.” In Handbook of Self-Regulation, edited by M. Boekaerts, P. Pintrich, and M. Zeidner, 13-39. San Diego, CA: Academic Press.

Zimmerman, Barry J., and Dale H. Schunk. 2011. “Self-Regulated Learning and Performance: An Introduction and an Overview.” In Handbook of Self-Regulation of Learning and Performance, edited by Barry J. Zimmerman and Dale Schunk H. New York: Routledge. 

Figure 1. Activity system (based on Engeström, 1987, 1999).

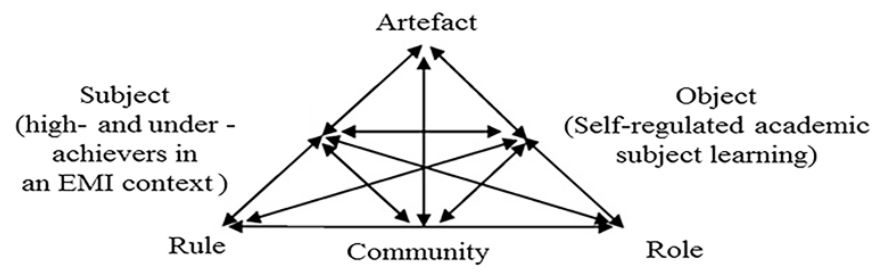

Figure 2. Example notes indicating the high achievers' use of symbols

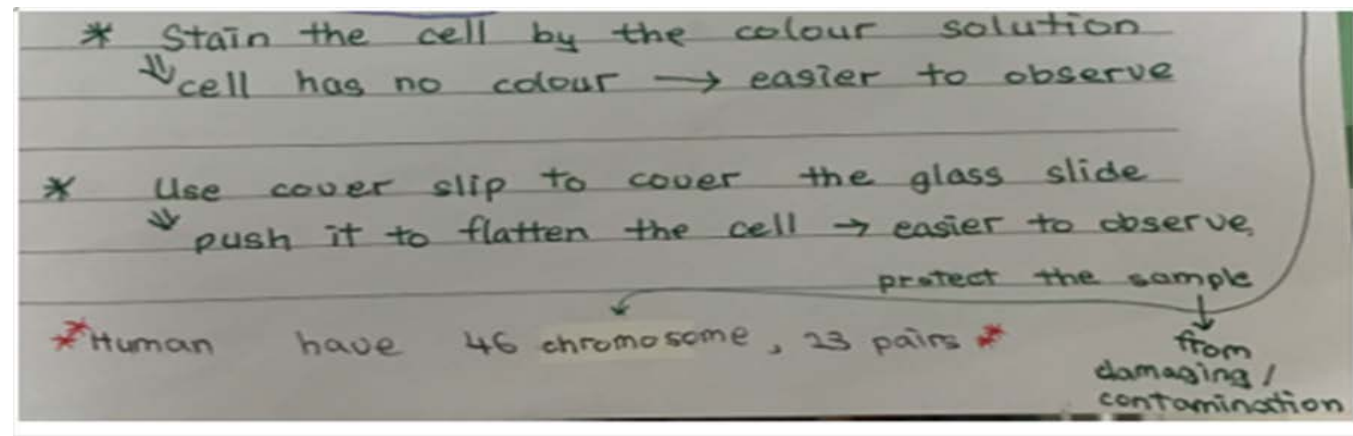

(Joey, Handbook)

Figure 3. Example notes indicating the underachievers' use of symbol

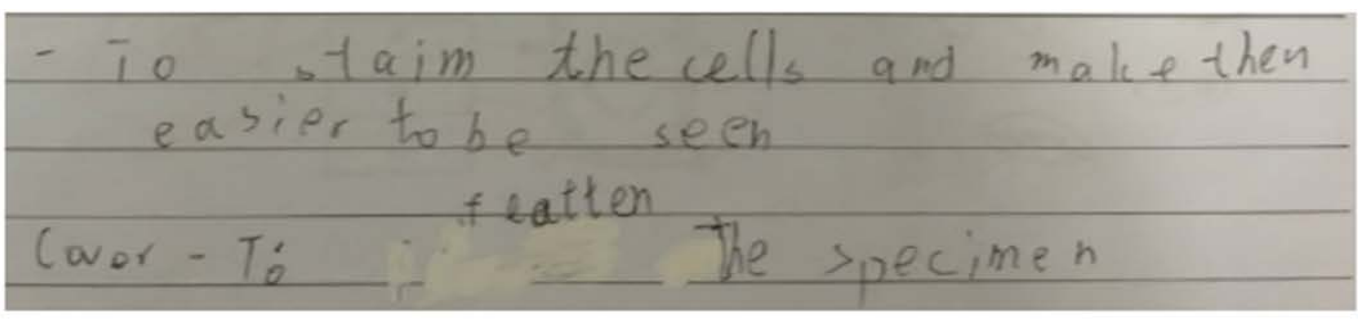

(Thomas, Handbook)

Figure 4. Activity system for EMI academic learning contexts 


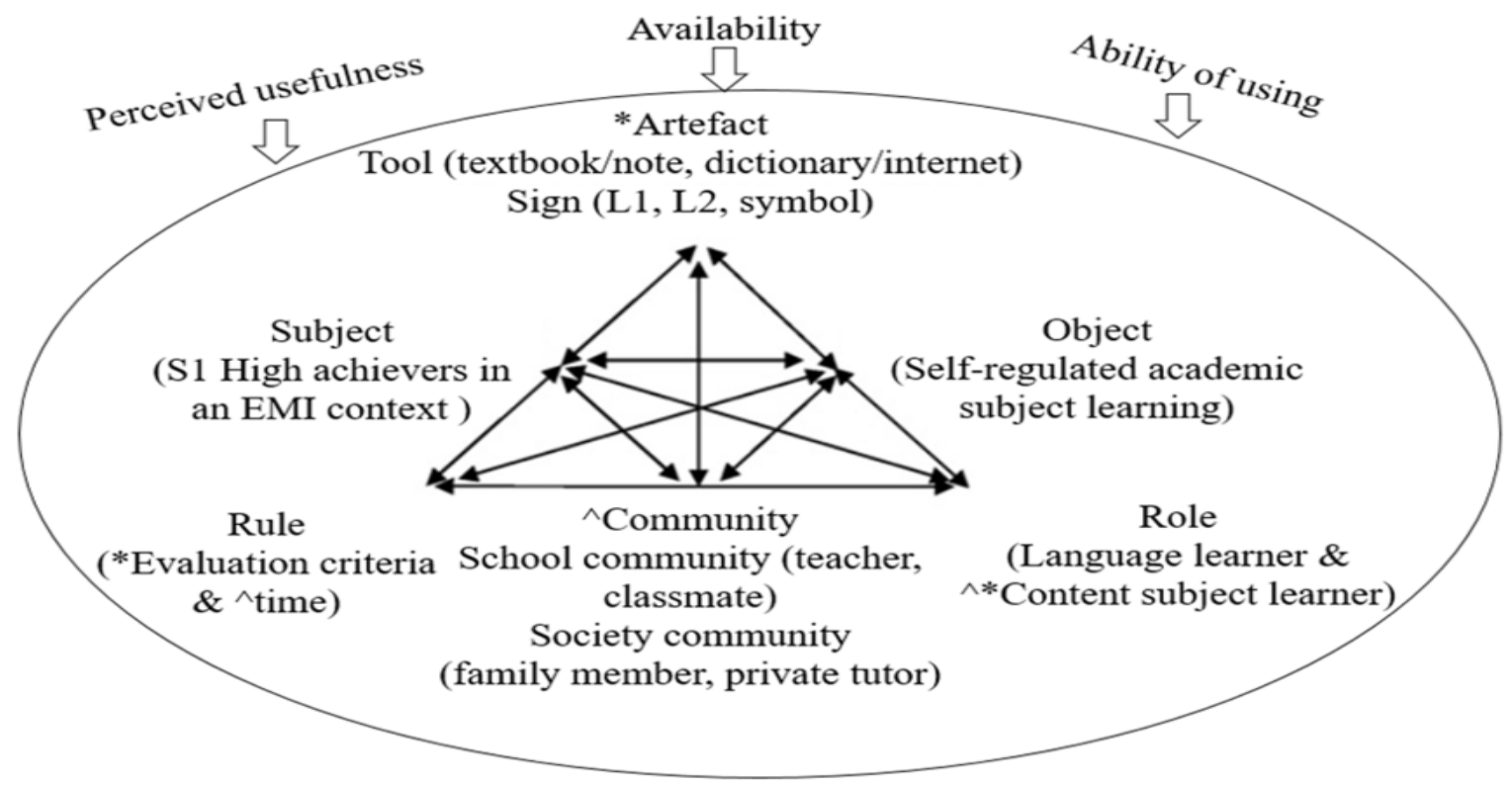

Note: '*' refers to the resources often used by the high achievers; '^’ refers to those often used by the underachievers. 